\title{
Quality of Work Life and Job Satisfaction Among Employees of Health
} Centers in Ahvaz, Iran

\author{
Effat Jahanbani, ${ }^{1,}$ Mostafa Mohammadi, ${ }^{2}$ Najmeh Noori Noruzi, ${ }^{3}$ and Fatemeh Bahrami ${ }^{4}$ \\ ${ }^{1}$ Department of Health Services Management, School of Health, Ahvaz Jundishapur University of Medical Sciences, Ahvaz, Iran \\ ${ }^{2}$ Student Research Committee, Ahvaz Jundishapur University of Medical Sciences, Ahvaz, Iran \\ ${ }^{3}$ Accreditation Expert, School of Health, Ahvaz Jundishapur University of Medical Sciences, Ahvaz, Iran \\ ${ }^{4}$ Department of Health Services Management, School of Health, Ahvaz Jundishapur University of Medical Sciences, Ahvaz, Iran \\ "Corresponding author: Effat Jahanbani, Department of Health Services Management, School of Health, Ahvaz Jundishapur University of Medical Sciences, Ahvaz, Iran. E-mail: \\ jahanbani1390@yahoo.com
}

Received 2017 June 11; Revised 2017 July 16; Accepted 2017 July 18.

\begin{abstract}
Background: The quality of working life (QWL) is increasingly considered in organizations interested in job satisfaction (JS) and enhancing organizational effectiveness. Objective: The current study aimed at investigating the QWL and JS in the employees of health centers in Ahvaz, Iran.

Methods: In the current descriptive-analytical study, 143 technical staff of health centers in East of Ahvaz were selected by the multistage random sampling method in 2015. Data were collected using 2 questionnaires. Data were analyzed through descriptive statistics, the Pearson correlation coefficient and multiple linear regression with SPSS version 21.

Results: Overall, the Walton QWL questionnaire scored 72.95 and the JS survey scored 126.08 were in the moderate level in the current study. There was a significant relationship between QWL and JS $(\mathrm{P}=0.00)$.Moreover, there was a significant relationship between JS and all components of QWL $(\mathrm{P}=0.00)$. The highest and lowest correlation was related to social cohesion $(0.539)$ and safe environment (0.212), respectively. Results of the regression analysis showed that the QWL explained $39.6 \%$ of the variance affecting the JS $\left(\mathrm{R}^{2}=0.396, \mathrm{P}=0.00\right)$. Among the dimensions of $\mathrm{QWL}$, growth and security $(\beta=0.190, \mathrm{P}=0.03)$, rule of law $(\beta=0.277, \mathrm{P}=0.00)$ and social cohesion $(\beta=0.321, \mathrm{P}=0.00)$ explained the variance affecting the JS significantly.

Conclusions: Due to the highest correlation between JS and social cohesion, superintendent of health centers should strive to increase the JS through development of teamwork, respect, and group decision-making.
\end{abstract}

Keywords: Quality of Work Life, Job Satisfaction, Health Centers, Employees, Ahvaz

\section{Background}

In recent years, qualified working environments, known as essential conditions to strengthen human resources in the health systems, are considered by scientists and management professionals (1). The concept of quality of work life (QWL) was first discussed in the late 1960s (2). This range of theoretical concepts aimed at modifying the organizational problems. A review of the literature showed that a usual and accepted definition does not exist for QWL, and different variables such as organizational policies, leadership styles, procedures, and practices affect employees' attitudes and their QWL (3). Until the mid-1970s, the focus of QWL was only on the design and improvement of work (4), but according to the large influence of this concept on improving the employees job satisfaction (JS), as well as reducing absenteeism and delay (5), it made QWL an important topic in many organizations including healthcare centers from the 1970s onwards (6).

QWL is the ability of staff to satisfy their personal needs through experiences they learn in the organization (7). Also, QWL is a criterion for the organizational skills development that provides triple factors of satisfaction and motivation, responsibility, and commitment to work (8). In fact, QWL includes any improvements in organizational culture that support the growth and development of people in the organization (9). The value system of QWL considers investment on people as the most important variable in strategic management equations. Also, fulfillment of employees needs leads to the long-term improvement and efficiency of organization (10). A number of experts believe that productivity stagnation and product quality in some of the industrial countries is due to the shortcomings in QWL and the changes made in the interests and excellence of staff(11).

On the other hand, JS is the effective orientation that 
an employee has toward his/her work. It can be considered as a global feeling about the job or as a related constellation of attitudes toward various aspects or facets of the job (12). Although in some texts QWL and JS are considered synonymous, much of management science specialists and industrial psychologists believe that QWL and JS are different in concept, and their difference is in the fact that JS is a result of QWL (13). Dana and Griffin (14) believe that QWL is similar to a pyramid that its concepts contains life satisfaction (at the top), job satisfaction (in the middle), and satisfaction with other aspects of work such as the satisfaction with wages, colleagues, and supervisors (in the bottom). Lau (15) compared the performance of companies known to have a high QWL. The results suggested that QWL had a profound impact on the employees job satisfaction.

The QWL affects JS and also personal life including family, leisure, and social needs. When the needs of employees are not fulfilled at the workplace, they likely experience more stress. This issue has negative effects on the wellbeing and job performance (16). Employees satisfaction and QWL directly affect the organizations' ability to serve customers, and if not measured, cannot be developed and maintained effectively. Dissatisfaction of QWL is a problem that almost damages all employees regardless of their status and position. Therefore, measuring the QWL gives employees a positive attitude towards work and organization, and improves productivity, intrinsic motivation, and organizational effectiveness (17).

Although JS and QWL are regarded as agents of organizations development in many researches, such studies are rare in health centers, particularly about QWL as a predictor of JS. Therefore, the current study was a pioneer attempt by the researchers to find out the factors of QWL that affect the JS among employees of health centers in Ahvaz, Iran.

\section{Objectives}

The current study aimed to investigate the impact of QWL on JS in technical employees of health centers in Ahvaz.

\section{Methods}

The current descriptive-analytical study was conducted in 2015.The study population included all technical staff of urban health centers in the East of Ahvaz. The sample size consisted of 143 subjects selected by the multistage random sampling method. The research instruments consisted of 2 questionnaires including the Walton QWL and the job descriptive index (JDI) JS. The Walton questionnaire contained 27 items in 8 dimensions; safe and healthy environment (3 items), fair compensation (3 items), total life space (3 items), social relevance ( 4 items), social cohesion (4 items), growth and security (3 items), development of human capabilities ( 4 items), and constitutionalism with 3 items. The Walton questionnaire was filled out by participants and they selected items related to their QWL on a 5-point Likert scale (very low, low, somewhat, high, and very high) with scores from 1 to 5 . The maximum and minimum scores were 135 and 27, respectively. Scores below 63 and above 99 showed low and high levels of QWL, respectively. JDI questionnaire was applied to measure JS. The JDI is one of the most popular instruments to measure JS with highly reliable results. It measures facets of JS in the area of supervision, work itself, co-worker relationship, and payment (18). JDI questionnaire consists of 39 items based on a 5-point Likert scale as strongly agree, agree, no idea, disagree, and strongly disagree. The scoring ranges 1 - 5. Scores below 91 and above 143 indicated low and high levels of JS, respectively. To analyze components of QWL and JDI, mean score $\geq 3.75$ was considered as a high level. Mean scores of 2.5 -3.5, as moderate level, and mean scores $<2.5$ were considered as low level. The validity of the questionnaires was confirmed by experts. Reliability of JDI ( $\mathrm{r}=$ $0.90)$ and $\mathrm{QWL}(\mathrm{r}=0.87)$ questionnaires was confirmed by Cronbach alpha. The data were analyzed using descriptive statistics, the Pearson correlation, the simple and multiple linear regression tests with SPSS version 16. In the current study, the level of significance was 0.05 .

\section{Results}

According to demographic findings, most of the participants were female (\%83.2), mostly within the age range of 31 - 40 years (40.6\%), and 51 and above (3.5\%) subjects were the least frequent. People with the work experience 11 - 20 years formed the largest group (51.7\%) and $81.8 \%$ were married. Also, 59.4\% had a bachelor's degree and only 9.1\% held a high school diploma. Family health (38.5\%) and occupational health (4.9\%) were the most and least positions.

The results showed that QWL with an average score of 72.95was in moderate level. Results also indicated that $36.4 \%$ of the respondents evaluated this variable in the low level, $62.9 \%$ in the moderate level, and only $0.7 \%$ of respondents evaluated it in the high level. Also, except the fair compensation and total life space with an average score of $<2.5$ that were in low level, other dimensions of QWL including safe and healthy working environment, opportunity for growth and security, the rule of law in the organization, social relevance, social cohesion, and the development of human capabilities with an average of 2.6 -2.9 were in moderate level (Table 1 ). 
Table 1. Quality of Work Life Scores Among Employees of Health Centers ${ }^{\mathrm{a}}$

\begin{tabular}{|c|c|c|c|c|c|c|c|c|}
\hline \multirow[t]{3}{*}{ Variable } & \multicolumn{6}{|c|}{ Level of Quality of Work Life } & \multirow[t]{3}{*}{ Mean } & \multirow[t]{3}{*}{ SD } \\
\hline & \multicolumn{2}{|c|}{ High } & \multicolumn{2}{|c|}{ Moderate } & \multicolumn{2}{|c|}{ Low } & & \\
\hline & Frequency & Percentage & Frequency & Percentage & Frequency & Percentage & & \\
\hline Adequate and fair compensation & - & - & 71 & 49.7 & 72 & 50.3 & 2.48 & \pm 0.68 \\
\hline Safe and healthy environment & 17 & 11.9 & 79 & 55.2 & 47 & 32.9 & 2.79 & \pm 0.83 \\
\hline Rule of law & 12 & 8.4 & 61 & 42.7 & 70 & 49 & 2.61 & \pm 0.80 \\
\hline Social relevance & 14 & 9.8 & 86 & 60.1 & 43 & 30.1 & 2.90 & \pm 0.80 \\
\hline Total life space & 2 & 1.4 & 72 & 50.3 & 69 & 48.3 & 2.43 & \pm 0.62 \\
\hline Social cohesion & 8 & 5.6 & 74 & 51.2 & 61 & 42.7 & 2.75 & \pm 0.69 \\
\hline Development of human capabilities & 8 & 5.6 & 80 & 55.9 & 55 & 38.5 & 2.78 & \pm 0.69 \\
\hline
\end{tabular}

Abbreviation: QWL, quality of work life

${ }^{\mathrm{a}} \mathrm{N}=143$.

In terms of JS, the results showed that overall JS with an average score of $\mathbf{1 2 6 . 0 8}$ was in intermediate level. Results also indicated that only $10.5 \%$ of the respondents said they were completely satisfied with their jobs and $13.3 \%$ of respondents were satisfied with their jobs in the low and $76.2 \%$ were in moderate levels (Table 2 ).

Results of the Kolmogorov-Smirnov test (KS) showed that the distribution of data of JS and QWL was normal (P $\geq 0.05$ ). Therefore, results of the Pearson correlation coefficient indicated a significant relationship between QWL and JS ( $\mathrm{P} \leq 0.05, \mathrm{r}=0.453)$. The results also showed a positive significant correlation between all components of QWL and JS $(\mathrm{P} \leq 0.05)$. The highest correlation was in social cohesion $(r=0.539)$ and the lowest in the safe and healthy work environment dimensions $(r=0.212)$ (Table 3).

To evaluate the importance of QWL to predict JS, the linear regression analysis was performed. This analysis aimed at quantifying the relationship between the dependent (JS) and independent (QWL) variables. Therefore, in the present study, QWL was considered as the predictor variable and JS as the criterion variable. According to the linear regression results, the $\mathrm{R}^{2}$ rate was 0.396 and $\mathrm{P}=0.00$. Therefore, 39.6\% of JS variance was explained by QWL(Table 4).

According to results of multiple regression analysis, using enter method, growth and security $(\beta=0.190, \mathrm{P}=$ $0.03)$, rule of law $(\beta=0.277, \mathrm{P}=0.00)$, and social cohesion $(\beta=0.321, \mathrm{P}=0.00)$ as aspects of $\mathrm{QWL}$ can significantly predict JS variance (Table 5).

$\mathrm{Y}(\mathrm{JS})=\mathrm{a}+\mathrm{b}($ growth $)+\mathrm{b}($ rule of law $)+\mathrm{b}$ (social cohesion $)=1.594+0.190+0.277+0.321$

\section{Discussion}

The current study mainly aimed to investigating the effect of QWL on JS in the technical staff of health centers. The QWL with the average score of 72.95 of 135 was in the moderate level. The average score of JS was 126.08 of 195. It meant that JS was in the intermediate level. In fact, the results showed that there is a need to improve the QWL and increase JS in Ahvaz health centers. These results were consistent with those of the previous studies (19-22).

The results also showed a significant relationship between QWL and JS. This finding was consistent with the results obtained by Torabi (22), Sheykhbardsiri (23), Tavakoli (24), Krueger (25), and Hua (26).

The $\mathrm{R}^{2}$ value in the current study (0.396) showed that QWL was a relatively good predictor for JS. Based on the Cohen recommendation, $\mathrm{R}^{2}$ values higher than 0.25 indicate a large variance in the model (27). According to the above results, it can be inferred that QWL was effective on JS.

In the present study, moderate level of QWL indicated that QWL was not much considered by the authorities. The results also revealed that among the components of QWL, fair payment was in a very low level. Similar results were also obtained in the study by Sheykhbardsiri (23). Results of the study by Pourghaz showed that most employees were unhappy with their salaries (28). Askari and Abasnejad believed that low level of salaries and failure to pay on-time were the main factors of dissatisfaction (29). Mogharab in his research suggested increasing the salaries as one of the important factors to improve QWL (30). Also, Goudarzvand Chegini and Mirdoozandeh believed that serious revisions should be made in the ratio between wages 
Table 2. Job Satisfaction Scores of the Health Centers Staff

\begin{tabular}{|c|c|c|c|c|c|c|c|c|}
\hline \multirow[t]{3}{*}{ Variable } & \multicolumn{6}{|c|}{ Level of Job Satisfaction } & \multirow[t]{3}{*}{ Mean } & \multirow[t]{3}{*}{ SD } \\
\hline & \multicolumn{2}{|c|}{ High } & \multicolumn{2}{|c|}{ Moderate } & \multicolumn{2}{|c|}{ Low } & & \\
\hline & Frequency & Percentage & Frequency & Percentage & Frequency & Percentage & & \\
\hline Payment & 5 & 3.5 & 31 & 21.7 & 107 & 74.8 & 2.12 & \pm 0.78 \\
\hline Supervision & 64 & 44.8 & 55 & 38.5 & 24 & 16.8 & 3.42 & \pm 0.95 \\
\hline Co-workers & 78 & 54.5 & 62 & 43.4 & 3 & 2.1 & 3.79 & \pm 0.66 \\
\hline Promotion & 22 & 15.4 & 53 & 37.1 & 68 & 47.6 & 2.61 & \pm 0.96 \\
\hline Job nature & 51 & 35.7 & 79 & 55.2 & 13 & 9.1 & 3.48 & \pm 0.64 \\
\hline Overall J S & 15 & 10.5 & 109 & 76.2 & 19 & 13.3 & 126.08 & \pm 19.8 \\
\hline
\end{tabular}

Abbreviation: JS, Job satisfaction.

${ }^{\mathrm{a}} \mathrm{N}=143$.

Table 3. Correlation Coefficient of the Quality of Work Life and Job Satisfaction

\begin{tabular}{|c|c|c|}
\hline Variable & $\mathbf{r}$ & P Value \\
\hline Adequate and fair payment & $0.278^{\mathrm{a}}$ & 0.001 \\
\hline Safe and healthy environment & $0.212^{\mathrm{a}}$ & 0.01 \\
\hline Human capacity & $0.349^{\mathrm{a}}$ & 0.000 \\
\hline Continue growth & $0.393^{\mathrm{a}}$ & 0.000 \\
\hline Social cohesion & $0.539^{\mathrm{a}}$ & 0.000 \\
\hline Life space & $0.290^{\mathrm{a}}$ & 0.000 \\
\hline Rule of law & $0.506^{\mathrm{a}}$ & 0.000 \\
\hline Social relevance & $0.360^{\mathrm{a}}$ & 0.000 \\
\hline Overall QWL & $0.453^{\mathrm{a}}$ & 0.000 \\
\hline
\end{tabular}

${ }^{\mathrm{a}} \mathrm{P} \leq 0.05$.

Table 4. Model Summary of Simple Linear Regression

\begin{tabular}{lcccc}
\hline Model & R & R square $\left(\mathbf{R}^{2}\right)$ & Adjusted $\mathbf{R}^{2}$ & Sig \\
\hline $\mathbf{1}$ & $0.629^{\mathrm{a}}$ & 0.396 & 0.360 & 10.989 \\
\hline
\end{tabular}

${ }^{\text {a }}$ Predictor; (constant), quality of work life.

${ }^{\mathrm{b}} \mathrm{P}<0.05$. 
Table 5. Results of Multiple Regression Analysis

\begin{tabular}{|c|c|c|c|c|c|}
\hline Predictor Variable & B & $\beta$ eta & t Value & sig & Tolerance \\
\hline Constant coefficient $^{\mathbf{a}}$ & 1.594 & & 7.640 & 0.000 & \\
\hline Adequate and fair payment & 0.070 & 0.094 & 1.233 & 0.22 & 0.783 \\
\hline Safe and healthy environment & -0.067 & -0.109 & -1.294 & 0.19 & 0.641 \\
\hline Growth and security & 0.125 & 0.190 & 2.196 & $0.03^{\mathrm{b}}$ & 0.603 \\
\hline Social relevance & -0.30 & -0.047 & -0.489 & 0.62 & 0.489 \\
\hline Life space & 0.063 & 0.076 & 1.013 & 0.31 & 0.792 \\
\hline Social cohesion & 0.236 & 0.321 & 3.455 & $0.00^{\mathrm{b}}$ & 0.523 \\
\hline Development of human capabilities & 0.076 & 0.00 & 0.00 & 0.99 & 0.643 \\
\hline
\end{tabular}

${ }^{a}$ Predictor; constant, quality of work life; criterion variable, job satisfaction.

${ }^{\mathrm{b}} \mathrm{P} \leq 0.05$.

and the community standards in terms of inflation, supply, and demand (31).

Life space as another component of QWL was ranked in very low level. Saedi believed that factors affecting the improvement of the life space within the organization should be reviewed and strengthened (32).

The results of the current study revealed a positive relationship between JS and the 8 dimensions of QWL. These results were consistent with those of the previous studies (31, 33). Close examination indicated that social cohesion had the highest coefficient correlation, followed by the rule of law, growth and security, social relevance, human capacity, life space, fair payment, and healthy environment.

Social cohesion was an important factor affecting JS. Social cohesion refers to creating a suitable working atmosphere to strengthen the feeling of belonging to the organization. It also teaches the staff how to effectively participate in the activities of organization and with the other members of organization. Thus, managers should create a good working atmosphere for the participation of employees.

The rule of law provides freedom of speech without fear from responses of supervisors (23). Therefore, according to the results of the current study, it was suggested that the organizations should provide the employees the freedom to express their constructive suggestions without fear of negative reactions of directors. And staff should believe in the rule of law in their organizations (31).

To strengthen growth and security as one of the predictors of JS, organizations should focus on autonomy of staff and by providing the required information and improving the skills of employees in the work environment increase the individual capabilities.The lowest correlation was observed in the fair payment component. In fact, this result indicated that contrary to the belief of many managers, salary was not the main cause of staff satisfaction. This result was consistent with the results of the study by Goudarzvand Chegini and Mirdoozandeh (31).

The obtained results indicated that managers should pay more attention to the factors beyond physical and financial ones to satisfy the employees. As previously mentioned, JS among health workers in East of Ahvaz was in the moderate level. Also the greatest satisfaction was related to the co-work component. This finding indicated that the atmosphere of health centers in Ahvaz was friendly and intimate. The results were consistent with those of the study by Pourqaz et al. (28).

\subsection{Conclusion}

In the current study, there was a positive significant relationship between QWL and JS; also QWL was a good predictor for JS. Also, the results revealed that among the aspects of QWL, the highest correlation was related to social cohesion, rule of law, and growth, and security. Therefore, to enhance and strengthen social cohesion, it was suggested that various ideas should be strengthened in health centers, team working considered, and the relationship between staff should be taken seriously. Also, serious attention should be paid to the rule of law and rights of employees should be respected. Moreover, since the growth and security was one of the important aspects of QWL, the health centers managers should pay more attention to the development of human capabilities in the organizations.

One of the limitations of the current study was using only the questionnaires to determine QWL and JS. Although QWL and JDI questionnaires were valid and reliable, the researchers cannot investigate all aspects of these 
variables using the questionnaire tool. Hence, in this regard some qualitative studies or combined studies should also be performed.

\section{Acknowledgments}

Authors express their thanks to the officials, as well as all employees of health centers in East Ahvaz for their support and participation in the study.

\section{Footnotes}

Authors' Contribution: Effat Jahanbani and Mostafa Mohammadi: developing the study concept, design, and methods; Mostafa Mohammadi: data collection and analysis; Effat Jahanbani: interpretation of the study data; Fatemeh Bahrami: writing the primary draft of the manuscript; all authors contributed to the revision of the manuscript and read and approved the final version.

Conflicts of Interest: The authors declared no conflict of interest.

Funding/Support: The study was supported by the student research committee, Ahvaz Jundishapur University of Medical Sciences, Iran (Grant no. 32-S93).

\section{References}

1. Lees M, Kearns S. Improving work life quality: A diagnostic approach model. Health care quarterly online case study Longwood publishing. 2005;1(2):1-5.

2. Che Rose R, Beh L, Uli J, Idris K. An analysis of quality of work life (qwl) and career- related variables. American J Applied Sciences. 2006;3(12):2151-9. doi: 10.3844/ajassp.2006.2151.2159.

3. Martel JP, Dupuis G. Quality of work life: Theoretical and methodological problems, and presentation of a new model and measuring instrument. Social Indicat Res. 2006;77(2):333-68. doi: 10.1007/s11205004-5368-4.

4. Koonmee K, Singhapakdi A, Virakul B, Lee DJ. Ethics institutionalization, quality of work life, and employee job-related outcomes: A survey of human resource managers in Thailand.JBus Res. 2010;63(1):206. doi: 10.1016/j.jbusres.2009.01.006.

5. Dolan SL, Garcia S, Cabezas C, Tzafrir SS. Predictors of "quality of work" and "poor health" among primary health-care personnel in Catalonia: evidence based on cross-sectional, retrospective and longitudinal design. Int J Health Care Qual Assur. 2008;21(2):203-18. doi: 10.1108/09526860810859058. [PubMed:18578204].

6. Khaghanizadeh M, Ebadi A, Rahmani M. The study of relationship between job stress and quality of work life of nurses in military hospitals. J Mil Med. 2008;10(3):175-84.

7. Hatam N, Lotfi M, Kavosi Z, Tavakoli A. The relationship between quality of work life and human resource productivity in knowledge workers. J Health Manage Informatic. 2014;1(3):59-65.

8. BazazJazayeri S, Pardakhtchi M. Measuring the work-life quality model of employees in an organizations. JManag Sci Iran.2007;(5):12351.
9. Dockel A, Basson JS, Coetzee M. The effect of retention factors on organisational commitment: An investigation of high technology employees. SA J Human Resource Manag. 2006;4(2). doi 10.4102/sajhrm.v4i2.91.

10. Richards B, O'Brien T, Akroyd D. Predicting the organizational commitment of marketing education and health occupations education teachers by work related rewards. J Ind Teach Educ. 1994.

11. Lawler EE. From job-based to competency-based organizations. JOrganization Behav. 1994;15(1):3-15. doi:10.1002/job.4030150103.

12. Lu H, Barriball KL, Zhang X, While AE. Job satisfaction among hospital nurses revisited: a systematic review. Int J Nurs Stud. 2012;49(8):101738. doi: 10.1016/j.ijnurstu.2011.11.009. [PubMed: 22189097].

13. Sirgy MI, Efraty D, Siegel P, Lee DJ.A new measure of quality of work life (QWL) based on need satisfaction and spillover theories. Social Indicat Res. 2001;55(3):241-302.

14. Danna K, Griffin RW. Health and well-being in the workplace: A review and synthesis of the literature. J Manag. 2016;25(3):357-84. doi $10.1177 / 014920639902500305$.

15. Lau RSM. Quality of work life and performance - An ad hoc investigation of two key elements in the service profit chain model. Int J Service Industry Manag. 2000;11(5):422-37. doi:10.1108/09564230010360164.

16. Emadzadeh MK, Khorasani M, Nematizadeh F. Assessing the quality of work life of primary school teachers in Isfahan city. Interdisciplinary J Contemporary Res Business. 2012;3(9):438-48.

17. Shariat H, Sheikhy A, Shojaeian R, Salari B. Studying the relationship between quality of work life and organizational commitment in duty and overtime hours. Int J Basic Sci Appl Res.

18. Onukwube HN. Correlates of job satisfaction amongst quantity surveyors in consulting firms in Lagos, Nigeria. Construction Economics Building. 2012;12(2):54.

19. Kermansaravi F, Navidian A, Navabi Rigi S, Yaghoubinia F. The relationship between quality of work life and job satisfaction of faculty members in Zahedan University of Medical Sciences. Glob J Health Sci. 2014;7(2):228-34. doi:10.5539/gihs.v7n2p228. [PubMed: 25716392].

20. Koushki MS, Arab M. Quality of working life and its relation with productivity of nurses' performance in Shahid Beheshti University of Medical Sciences hospitals. J School Public Health Institute Public Health Res. 2013;10(4):81-90.

21. Sayyadi TH, Jamali R, Mansouri H. Examination of relationship between quality-of-work-life and organizational commitment (case study: Yazd education departments employees). J EDUC. 2009.

22. Fatehi B, Karimi A, Pour EG, Pour KA, Azizi B. Impact of quality of work life on job satisfaction. Int J Sport Stud. 2015;5(1):79-86.

23. Sheykhbardsiri H, Amini zadeh M, Vali L, Aliesmaeli M, Amini Zadeh G, Amini Zadeh A. The relationship between the quality of worklife and organizational commitment among personnel of emergency medical services. J Manage Med Inf Sch. 2013;1(1):38-46.

24. Tavakoli ALM, Davoudnia A, Alizadeh Zoeram A. Investigating the relationship between the Walton,s quality work life factors and job satisfaction (case of: Gas company of Razavi Khorasan province). Manag J. 2013;5(9):90-103.

25. Krueger P, Brazil K, Lohfeld L, Edward HG, Lewis D, Tjam E. Organization specific predictors of job satisfaction: findings from a Canadian multi-site quality of work life cross-sectional survey. BMC Health Serv Res. 2002;2(1):6. [PubMed: 11914162].

26. Hua J. A study of relationship on bureau of investigation officials, quality of work life, work pressure and job satisfaction. Public Affairs Management. 2006.

27. Zarei E, Daneshkohan A, Khabiri R, Arab M. The Effect of Hospital Service Quality on Patient's Trust. Iran Red Crescent Med J. 2015;17(1). e17505. doi: 10.5812/ircmj.17505. [PubMed: 25763258].

28. Pourghaz A, Nastizaie N, Hezare Moghaddam M. Job satisfaction of nursing staff in hospitals of Zahedan. J Urmia Nursing Midwifery Faculty. 2010;8(3):143-8.

29. Askari F, Abbasnezhad A. The study of professional stressor factors in nursing and midwifery community. Horizon Med Sci. 2007;12(4):12-8. 
30. Reyasi H. Work life quality of nurses working in educational hospitals affiliated to Birjand University of Medical Sciences, 2012. Modern Care J. 2013;10(1):84-90.

31. Goudarznand-Chegini M, Mirdoozandeh SG. Relationship between quality of work-life and job satisfaction of the employees in public hospitals in Rasht. Zahedan J Res Med Sci. 2012;14(2):108-11.
32. Saedi S, Khalatbari J, Murray Najafabadi N. Relationship between quality of work life and organizational health with job satisfaction. J Modern Industrial/Organization Psychol. 2010;1(4):55-64.

33. Tabassum A. Interrelations between quality of work life dimensions and faculty member job satisfaction in the private universities of Bangladesh. European J Business Manag. 2012;4(2):78-89. 